\title{
Modeling Human Liver Biology Using Stem Cell-Derived Hepatocytes
}

\author{
Pingnan Sun ${ }^{1,2,3}$, Xiaoling Zhou ${ }^{1,2,3}$, Sarah L. Farnworth ${ }^{2}$, Arvind H. Patel ${ }^{3}$ and \\ David C. Hay ${ }^{2, *}$
}

1 Shantou University Medical College, Shantou 515041, China;

E-Mails: pingnan_sun@yahoo.com (P.S.); xiaolingsmiling_zhou@yahoo.com (X.Z.)

2 MRC Centre for Regenerative Medicine, University of Edinburgh, Edinburgh EH16 4UU, UK;

E-Mail: slfarnworth@hotmail.com

3 MRC-University of Glasgow Centre for Virus Research, University of Glasgow, Glasgow G11 5JR, UK; E-Mail: arvind.patel@glasgow.ac.uk

* Author to whom correspondence should be addressed; E-Mail: davehay@talktalk.net;

Tel.: +44-131-651-9549; Fax: +44-131-651-9501.

Received: 28 September 2013; in revised form: 28 October 2013 / Accepted: 30 October 2013 /

Published: 6 November 2013

\begin{abstract}
Stem cell-derived hepatocytes represent promising models to study human liver biology and disease. This concise review discusses the recent progresses in the field, with a focus on human liver disease, drug metabolism and virus infection.
\end{abstract}

Keywords: drug metabolism; liver disease; stem cell; stem cell-derived hepatocytes; cell based models

\section{Introduction}

The human liver has a multitude of functions. The cells which comprise the liver and perform those roles are termed parenchymal and non-parenchymal. Approximately $70 \%-80 \%$ of the liver is composed of the parenchymal cells known as hepatocytes. The non-parenchymal fraction make up the rest of the organ and are localized in the sinusoidal and biliary compartments of the tissue [1]. The hepatocyte compartment performs many metabolic and synthetic functions, for example storage and mobilization of sugars, maintenance of the blood clotting factors and the processing of drugs. Therefore, maintaining hepatic function is vital for normal physiology, and long-term damage to this compartment is 
detrimental to human health. Liver disease can be caused by a number of different stimuli, such as viral infection, excess alcohol or the exposure to prescription or recreational drugs. In the normal setting, the hepatocyte is capable of organ regeneration and restoration of normal function. However, in the chronic injury setting the residential stem cell population is required to restore liver mass and ultimately function [2].

Given the dire consequences of severe liver damage, a number of cell based models have been developed to predict the potential for human liver injury (for a review see [3]). Freshly isolated human primary hepatocytes (PHHs) are recognized as the "gold standard" for evaluating liver metabolism and drug toxicity [4]. PHHs express many of the essential drug metabolizing enzymes for several days in tissue culture following their isolation. However, enzyme expression drops off markedly during cell culture which can complicate biological interpretation [5,6]. In addition to their instability, PHHs widespread use is limited by their scarcity and quality [7].

To overcome the shortage and stability of PHHs, a number of different human hepatoma-derived cell lines have been established. In contrast to PHHs, hepatoma-derived cells are scalable, cheap to maintain and are easy to handle. However, those benefits are out-weighed by defects in key cell signaling pathways which result in inferior phenotype. For example, Huh7.5 cells are used to study Hepatitis C virus $(\mathrm{HCV})$ replication but are not ideal to study virus-host interaction due to defects in the retinoic acid-inducible gene 1 pathway [8]. Additionally, hepatoma-derived cell lines display limited capacity for drug metabolism due to poor cytochrome P450 gene expression [9-11]. With the advent of pluripotent stem cell technology, it is now possible to produce stem cell-derived hepatocyes at scale and from known genetic background. We believe that this has revolutionary potential for modern medicine (Figure 1) and discuss the potential of stem cells in more detail throughout the review.

Figure 1. Modeling human liver biology using stem cell-derived hepatocytes. Hepatocytes derived from pluripotent stem cells (embryonic stem cells and induced pluripotent stem (iPS) cells), adult stem cells, or somatic cells can be used for modeling human liver biology "in a dish". Examples of the use of this technology include, toxicity screening, disease modeling, viral infection and replication.

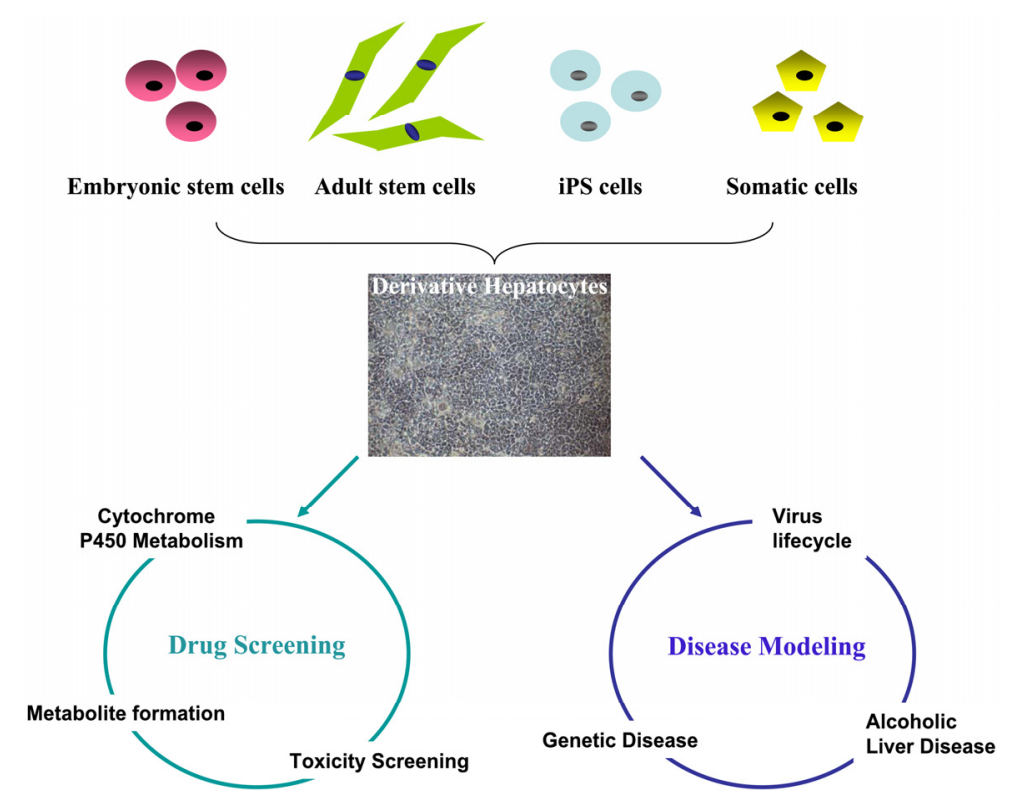




\section{Generation of In Vitro-Derived Hepatocytes from Stem Cell or Somatic Cells}

\subsection{Hepatocytes Derived from Human Embryonic Stem Cells (hESCs)}

hESCs are derived from the inner cell mass of preimplantation embryos [12]. They have the ability to self-renew, and at the same time retain the ability to differentiate to all three germ layers [13]. Therefore, it is possible to scale large numbers of stem cells and their derivatives for downstream application [14]. hESCs have been differentiated into functional hepatic endoderm using spontaneous or directed differentiation [15-18]. During spontaneous differentiation, hESCs are maintained in suspension to induce differentiation into embryoid bodies (EBs) [19]. Those EBs are further stimulated to differentiate toward the hepatocyte lineage using physiological cues [20]. While the process is resilient, the efficiency of stem cell-derived hepatocytes generated using this method is low and requires further enrichment [16,21]. During directed differentiation, hESCs are differentiated to hepatocytes in adherent and 2 dimensional monolayer culture. Several groups have confirmed this method is possible and more efficient than spontaneous differentiation [17,22,23]. In both procedures, definitive endoderm is specified from hESCs and then induced to differentiate along the hepatic lineage by the sequential addition of inducing factors. We have developed a highly efficient method to deliver functional hepatocytes which could be assayed in a high throughput format [18]. Since those early discoveries, we and others have delivered scalable populations of stem cell-derived hepatocytes using serum-free and synthetic components [24,25]. Most recently, exciting studies by Vosough et al. demonstrated scalable suspension culture for stem cell expansion and differentiation. Most notably, pluripotent stem cells were expanded and differentiated toward the hepatocyte lineage at a scale that would satisfy liver cell-based therapy requirements $[21,26]$.

\subsection{Hepatocytes Derived from Induced Pluripotent Stem Cells (iPSCs)}

Differentiated somatic cells can be reprogrammed to an ES-like state [27] termed induced pluripotent stem cells (iPSCs). As with the hESCs, iPSCs theoretically offer a potential source of somatic cells in large numbers [28]. Of note, iPSCs have been induced toward the hepatocyte lineage using similar protocols that were developed in hESCs [29]. Interestingly and in agreement with studies using hESCs, there are significant variations in iPSC hepatic differentiation capacity [29]. iPSC clones derived from peripheral blood cells were found to be comparable to dermal fibroblasts from the same individual, but differentiation capacity varied from donor to donor using a modified version of our procedure [18,30].

\subsection{Hepatocytes from Direct Reprogramming Somatic Cells}

Reprogramming of fibroblasts to iPSC demonstrated that somatic cells could be reprogrammed to a pluripotent stem cell state [31,32]. It has also been demonstrated that somatic cells are capable of trans-differentiation to heptocytes using specific sub sets of transcription factors. Murine somatic cells have been successfully reprogrammed to hepatocyte-like cells [33,34]. Hepatocytes were derived from mouse tail-tip fibroblasts and transduced with virus expressing Gata4, HNF1 $\alpha$ and Foxa3 [30]. In these studies there was a requirement for the inactivation of p19 (Arf) [33]. In a separate study, mouse embryonic and adult fibroblasts were trans-differentiated using combinations of HNF4 $\alpha$ plus Foxa1, 
Foxa2 or Foxa3 [34]. Importantly, the derivative hepatocytes exhibited similar function to primary hepatocytes. Encouragingly, trans-differentiated heaptocytes were transplanted in vivo and repopulated the livers of fumarylacetoacetate-hydrolase-deficient mice, rescuing almost half of recipients [33]. Most recently, the transcription factor cocktail was modified to HNF1 $\beta$ and Foxa3, which yielded a cell type reminiscent of bipotent hepatic stem cells [35]. Until now, the direct reprogramming to hepatocytes has not been accomplished in human cells, but this cannot be far off. In support of this, over expression of lineage-specific transcription factors has been shown to directly convert terminally differentiated cells into other lineages, including neurons, cardiomyocytes and blood progenitors [36-38].

\section{Modeling Human Drug Metabolism Using Stem Cell-Derived Hepatocytes}

\subsection{Drug Attrition}

The drug discovery process is a rocky road and pharmaceutical companies face major issues with drug attrition [39]. It is estimated that the average cost to bring a new drug to market ranges between $\$ 800$ million and $\$ 2$ billion [40]. Issues associated with cardiac and liver toxicity, among others, are a major concern during this process [41]. Therefore, human models, which accurately reflect physiology, could impact on the spiraling costs associated with drug development. As previously detailed, PHHs represent the "gold standard" [42], but their limited availability and stability restricts widespread use. A credible alternative for the future, are pluripotent stem cell-derived hepatocytes, which have already shown great potential in the determination of human drug metabolism and hepatotoxicity [43].

\subsection{Stem Cell-Derived Hepatocytes}

Drug metabolism in the liver can be divided into three phases. Phase I reactions are carried out by the cytochrome P450 enzymes (CYPs) which modify the chemical substrate via oxidation, reduction and/or hydrolysis. CYPs are the major enzymes involved in drug metabolism [44]. The major CYP enzymes involved in drug metabolism include; the CYP1A family, CYP2A6, CYP2B6, the CYP2C family, CYP2D6, CYP2E1, and the CYP3A family [45]. Among them, CYP3A4 is the most abundant isoform in human liver and has been estimated to be involved in the metabolism of approximately $50 \%$ of prescribed medicines [46]. Phase II reactions are conjugation reactions which modify drug and metabolite polarity, rendering the products more water soluble. Following this, the Phase III reactions are responsible for metabolite transport across the cell membrane. In this stage, transporters, such as multi-drug resistance-associated protein 2 and permeability glycoprotein, move metabolites across the cell barriers in an energy dependent process [47]. Phase I-III reactions are vital to normal hepatocyte function. Unfortunately, drug metabolism, conjugation and transport decrease with time in cell culture and has been attributed to sub-optimal tissue culture microenvironments [48]. Recently, our laboratory identified a synthetic polymer which delivers phenotypically stable hepatocyte populations for at least 15 days, in two dimensional and three-dimensional format. Importantly, the stem cell derived heaptocytes replated on this material displayed equivalence to the current gold standard demanded by regulatory authorities $[25,43]$. In addition to our approach, other groups have also studied human liver toxicity using stem cell derived hepatocytes. In a recent study by Yildirimman et al., stem cell-derived hepatocytes were exposed to numerous agents classified as noncarcinogens, genotoxic carcinogens, and 
nongenotoxic carcinogens [49]. Changes in hepatic transcriptome were analyzed using gene expression microarrays. Encouragingly, stem cell-derived hepatocytes correlated well with that of PHHs.

\section{Modeling Human Disease Using Stem Cell-Derived Hepatocytes}

\subsection{Modeling Human Genetic Liver Disorders}

Stem cell-derived hepatocytes generated from patients with metabolic liver diseases are a useful model for understanding the disease process. Various human inherited liver diseases such as: al-antitrypsin deficiency; Glucose-6-phosphate deficiency; LDL-receptor mutations; Crigler-Najjar-Syndrome; and Wilson's disease have been successfully modeled "in a dish" using iPS-derived hepatocytes from the patients [50-52]. In addition to understanding disease better, these models also provide useful platforms to screen for new drugs to better treat disease and therefore represent exciting advances.

\subsection{Hepatitis Virus Infection and Replication}

In addition to modeling inherited liver diseases, stem cell-derived hepatocytes have proved useful in delivering models for studying the lifecycle of hepatotropic viruses. This is very important as current approaches using human hepatoma cell culture to model hepatitis $\mathrm{C}$ virus (HCV) lifecycle has a number of drawbacks and as a result does not support the growth of clinical viral isolates. This precludes studies of many important host-pathogen interactions that are crucial for a more detailed understanding of viral life cycle and pathogenesis. This has necessitated the development of models which are phenotypically closer to human hepatocytes. Encouragingly, stem cell-derived hepatocytes have been shown to support the entire life cycle of the HCV including viral entry, replication, production and release of progeny virus, albeit at low levels [53-55]. However, there are still few reports on applying stem cell-derived hepatocytes to other hepatotropic viruses including hepatitis B virus (HBV) and hepatitis D virus (HDV) which affect more than 2 billion people worldwide [56-58]. A suitable model for HBV, and the associated, HDV are needed to provide key clues to viral lifecycle and pathogenesis. Of note, sodium taurocholate, a transport polypeptide, was recently discovered as a new functional receptor of HBV and HDV [59] and represents substantial progress in this field. We believe that stem cell-derived hepatocytes offer promising models for HBV and HDV studies.

Another important goal of developing such virus models, is to further our understanding of the affect that genetic background has on viral pathogenesis. Certain individuals are prone to developing chronic viral infection while others can efficiently clear the virus. A reasonable explanation may lie in differences in immune factors or viral receptor expression. However, the true reasons for these different responses are still largely unresloved. We believe that stem cell derived models, from defined genetic origin, may provide insight into the disease process and currently available treatments. In the future, such models could facilitate the development of new anti-viral drugs, which can be tailored to the patient's genetics. 


\subsection{Alcoholic Liver Disease}

Liver disease, such as fatty liver, cirrhosis, and hepatocellular carcinoma are closely associated with alcohol abuse [60]. To investigate the mechanisms by which alcohol affects liver biology, many laboratories have used animal models, histology, primary human hepatocytes and hepatoma cell lines [61]. However, these models do not accurately reflect the situation within human liver as alcoholic liver disease pre-disposition is largely dependent on the individual's genetics.

Human hepatocytes, are the major cell type in the liver which undertakes alcohol metabolism. Hepatocytes degrade alcohol into aldehyde by alcohol dehydrogenase and catalyze the oxidation of aldehydes to carboxylic acids by aldehyde dehydrogenase. In addition to tissue damage, alcohol and its metabolites, can trigger the innate immune response, contributing to inflammation [3,62]. Most recently, stem cell derived heaptocytes have been shown to have an important role to play in modeling human hepatocyte response to alcohol. Alcohol was found to induce apoptosis and disturb stem cell-derived hepatocyte differentiation as well as impair the survival and proliferation of stem cell-derived hepatocytes [63]. This has raised the possibility that by applying stem cell-derived hepatocytes from defined genetic origin, in a context of ALD, will allow the more detailed analysis of an individual's response to alcohol metabolism and disease progression.

\section{Challenge and Prospect of Stem Cell-Derived Hepatocytes}

Many methods have been devised to efficiently generate stem cell-derived hepatocytes from hESCs or hiPSCs (for a review see Szkolnicka et al. 2013 [64]). There are still challenges to be faced when using stem cell-derived hepatocytes to model human liver physiology. Those challenges include, bona fide differentiation, cost effective scale up and reliable and stable performance. That being said, mature cell populations are emerging which deliver reliable biological readouts and represent exciting advances in the field, likely to impact on modern medicine [65].

\section{Acknowledgments}

This work was supported by the MRC (Ref. MR/K008757/1.) and NSFC (Ref. 81261130312) Stem Cell Partnership scheme.

\section{Conflicts of Interest}

David Hay, is a founder, shareholder and CSO of FibromEd Products limited.

\section{References}

1. Kmiec, Z. Cooperation of liver cells in health and disease. Adv. Anat. Embryol. Cell Biol. 2001, 161, $1-151$.

2. Espanol-Suner, R.; Carpentier, R.; van Hul, N.; Legry, V.; Achouri, Y.; Cordi, S.; Jacquemin, P.; Lemaigre, F.; Leclercq, I.A. Liver progenitor cells yield functional hepatocytes in response to chronic liver injury in mice. Gastroenterology 2012, doi:10.1053/j.gastro.2012.08.024. 
3. Thiele, G.M.; Klassen, L.W.; Tuma, D.J. Formation and immunological properties of aldehyde-derived protein adducts following alcohol consumption. Methods Mol. Biol. 2008, 447, 235-257.

4. Lecluyse, E.L.; Alexandre, E. Isolation and culture of primary hepatocytes from resected human liver tissue. Methods Mol. Biol. 2010, 640, 57-82.

5. Gomez-Lechon, M.J.; Donato, M.T.; Castell, J.V.; Jover, R. Human hepatocytes in primary culture: The choice to investigate drug metabolism in man. Curr. Drug Metab. 2004, 5, 443-462.

6. Hewitt, N.J.; Lechon, M.J.; Houston, J.B.; Hallifax, D.; Brown, H.S.; Maurel, P.; Kenna, J.G.; Gustavsson, L.; Lohmann, C.; Skonberg, C.; et al. Primary hepatocytes: Current understanding of the regulation of metabolic enzymes and transporter proteins, and pharmaceutical practice for the use of hepatocytes in metabolism, enzyme induction, transporter, clearance, and hepatotoxicity studies. Drug Metab. Rev. 2007, 39, 159-234.

7. Donato, M.T.; Lahoz, A.; Castell, J.V.; Gomez-Lechon, M.J. Cell lines: A tool for in vitro drug metabolism studies. Curr. Drug Metab. 2008, 9, 1-11.

8. Meylan, E.; Curran, J.; Hofmann, K.; Moradpour, D.; Binder, M.; Bartenschlager, R.; Tschopp, J. Cardif is an adaptor protein in the RIG-I antiviral pathway and is targeted by hepatitis $\mathrm{C}$ virus. Nature 2005, 437, 1167-1172.

9. Jover, R.; Bort, R.; Gomez-Lechon, M.J.; Castell, J.V. Re-expression of C/EBP alpha induces CYP2B6, CYP2C9 and CYP2D6 genes in HepG2 cells. FEBS Lett. 1998, 431, 227-230.

10. Schrem, H.; Klempnauer, J.; Borlak, J. Liver-enriched transcription factors in liver function and development. Part II: The C/EBPs and D site-binding protein in cell cycle control, carcinogenesis, circadian gene regulation, liver regeneration, apoptosis, and liver-specific gene regulation. Pharmacol. Rev. 2004, 56, 291-330.

11. Wong, N.; Lai, P.; Pang, E.; Leung, T.W.; Lau, J.W.; Johnson, P.J. A comprehensive karyotypic study on human hepatocellular carcinoma by spectral karyotyping. Hepatology 2000, 32, 1060-1068.

12. Thomson, J.A.; Itskovitz-Eldor, J.; Shapiro, S.S.; Waknitz, M.A.; Swiergiel, J.J.; Marshall, V.S.; Jones, J.M. Embryonic stem cell lines derived from human blastocysts. Science 1998, 282, 1145-1147.

13. Reubinoff, B.E.; Pera, M.F.; Fong, C.Y.; Trounson, A.; Bongso, A. Embryonic stem cell lines from human blastocysts: Somatic differentiation in vitro. Nat. Biotechnol. 2000, 18, 399-404.

14. Zhou, W.; Hannoun, Z.; Jaffray, E.; Medine, C.N.; Black, J.R.; Greenhough, S.; Zhu, L.; Ross, J.A.; Forbes, S.; Wilmut, I.; et al. SUMOylation of HNF4 $\alpha$ regulates protein stability and hepatocyte function. J. Cell Sci. 2012, 125, 3630-3635.

15. Lavon, N.; Benvenisty, N. Study of hepatocyte differentiation using embryonic stem cells. J. Cell. Biochem. 2005, 96, 1193-1202.

16. Basma, H.; Soto-Gutierrez, A.; Yannam, G.R.; Liu, L.; Ito, R.; Yamamoto, T.; Ellis, E.; Carson, S.D.; Sato, S.; Chen, Y.; et al. Differentiation and transplantation of human embryonic stem cell-derived hepatocytes. Gastroenterology 2009, 136, 990-999.

17. Duan, Y.; Catana, A.; Meng, Y.; Yamamoto, N.; He, S.; Gupta, S.; Gambhir, S.S.; Zern, M.A. Differentiation and enrichment of hepatocyte-like cells from human embryonic stem cells in vitro and in vivo. Stem Cells 2007, 25, 3058-3068. 
18. Hay, D.C.; Fletcher, J.; Payne, C.; Terrace, J.D.; Gallagher, R.C.; Snoeys, J.; Black, J.R.; Wojtacha, D.; Samuel, K.; Hannoun, Z.; et al. Highly efficient differentiation of hESCs to functional hepatic endoderm requires ActivinA and Wnt3a signaling. Proc. Natl. Acad. Sci. USA 2008, 105, 12301-12306.

19. Itskovitz-Eldor, J.; Schuldiner, M.; Karsenti, D.; Eden, A.; Yanuka, O.; Amit, M.; Soreq, H.; Benvenisty, N. Differentiation of human embryonic stem cells into embryoid bodies compromising the three embryonic germ layers. Mol. Med. 2000, 6, 88-95.

20. Imamura, T.; Cui, L.; Teng, R.; Johkura, K.; Okouchi, Y.; Asanuma, K.; Ogiwara, N.; Sasaki, K. Embryonic stem cell-derived embryoid bodies in three-dimensional culture system form hepatocyte-like cells in vitro and in vivo. Tissue Eng. 2004, 10, 1716-1724.

21. Vosough, M.; Omidinia, E.; Kadivar, M.; Shokrgozar, M.A.; Pournasr, B.; Aghdami, N.; Baharvand, H. Generation of functional hepatocyte-like cells from human pluripotent stem cells in a scalable suspension culture. Stem Cells Dev. 2013, 22, 2693-2705.

22. Hay, D.C.; Zhao, D.; Ross, A.; Mandalam, R.; Lebkowski, J.; Cui, W. Direct differentiation of human embryonic stem cells to hepatocyte-like cells exhibiting functional activities. Cloning Stem Cells 2007, 9, 51-62.

23. Agarwal, S.; Holton, K.L.; Lanza, R. Efficient differentiation of functional hepatocytes from human embryonic stem cells. Stem Cells 2008, 26, 1117-1127.

24. Hannoun, Z.; Fletcher, J.; Greenhough, S.; Medine, C.; Samuel, K.; Sharma, R.; Pryde, A.; Black, J.R.; Ross, J.A.; Wilmut, I.; et al. The comparison between conditioned media and serum-free media in human embryonic stem cell culture and differentiation. Cell Reprogram 2010, 12, 133-140.

25. Hay, D.C.; Pernagallo, S.; Diaz-Mochon, J.J.; Medine, C.N.; Greenhough, S.; Hannoun, Z.; Schrader, J.; Black, J.R.; Fletcher, J.; Dalgetty, D.; et al. Unbiased screening of polymer libraries to define novel substrates for functional hepatocytes with inducible drug metabolism. Stem Cell Res. 2011, 6, 92-102.

26. Hay, D.C. Rapid and scalable human stem cell differentiation: Now in 3D. Stem Cells Dev. 2013, 22, 2691-2692.

27. Takahashi, K.; Yamanaka, S. Induction of pluripotent stem cells from mouse embryonic and adult fibroblast cultures by defined factors. Cell 2006, 126, 663-676.

28. Dalgetty, D.M.; Medine, C.N.; Iredale, J.P.; Hay, D.C. Progress and future challenges in stem cell-derived liver technologies. Am. J. Physiol. Gastrointest. Liver Physiol. 2009, 297, G241-G248.

29. Sullivan, G.J.; Hay, D.C.; Park, I.H.; Fletcher, J.; Hannoun, Z.; Payne, C.M.; Dalgetty, D.; Black, J.R.; Ross, J.A.; Samuel, K.; et al. Generation of functional human hepatic endoderm from human induced pluripotent stem cells. Hepatology 2010, 51, 329-335.

30. Kajiwara, M.; Aoi, T.; Okita, K.; Takahashi, R.; Inoue, H.; Takayama, N.; Endo, H.; Eto, K.; Toguchida, J.; Uemoto, S.; et al. Donor-dependent variations in hepatic differentiation from human-induced pluripotent stem cells. Proc. Natl. Acad. Sci. USA 2012, 109, 12538-12543.

31. Takahashi, K.; Tanabe, K.; Ohnuki, M.; Narita, M.; Ichisaka, T.; Tomoda, K.; Yamanaka, S. Induction of pluripotent stem cells from adult human fibroblasts by defined factors. Cell 2007, 131, 861-872. 
32. Yu, J.; Vodyanik, M.A.; Smuga-Otto, K.; Antosiewicz-Bourget, J.; Frane, J.L.; Tian, S.; Nie, J.; Jonsdottir, G.A.; Ruotti, V.; Stewart, R.; et al. Induced pluripotent stem cell lines derived from human somatic cells. Science 2007, 318, 1917-1920.

33. Huang, P.; He, Z.; Ji, S.; Sun, H.; Xiang, D.; Liu, C.; Hu, Y.; Wang, X.; Hui, L. Induction of functional hepatocyte-like cells from mouse fibroblasts by defined factors. Nature 2011, 475, 386-389.

34. Sekiya, S.; Suzuki, A. Direct conversion of mouse fibroblasts to hepatocyte-like cells by defined factors. Nature 2011, 475, 390-393.

35. Yu, B.; He, Z.-Y.; You, P.; Han, Q.-W.; Xiang, D.; Chen, F.; Wang, M.-J.; Liu, C.-C.; Lin, X.-W.; Borjigin, U. Reprogramming fibroblasts into bipotential hepatic stem cells by defined factors. Cell Stem Cell 2013, 13, 328-340.

36. Vierbuchen, T.; Ostermeier, A.; Pang, Z.P.; Kokubu, Y.; Sudhof, T.C.; Wernig, M. Direct conversion of fibroblasts to functional neurons by defined factors. Nature 2010, 463, $1035-1041$.

37. Ieda, M.; Fu, J.D.; Delgado-Olguin, P.; Vedantham, V.; Hayashi, Y.; Bruneau, B.G.; Srivastava, D. Direct reprogramming of fibroblasts into functional cardiomyocytes by defined factors. Cell 2010, 142, 375-386.

38. Szabo, E.; Rampalli, S.; Risueno, R.M.; Schnerch, A.; Mitchell, R.; Fiebig-Comyn, A.; Levadoux-Martin, M.; Bhatia, M. Direct conversion of human fibroblasts to multilineage blood progenitors. Nature 2010, 468, 521-526.

39. Kola, I.; Landis, J. Can the pharmaceutical industry reduce attrition rates? Nat. Rev. Drug Discov. 2004, 3, 711-715.

40. Orloff, J.; Douglas, F.; Pinheiro, J.; Levinson, S.; Branson, M.; Chaturvedi, P.; Ette, E.; Gallo, P.; Hirsch, G.; Mehta, C.; et al. The future of drug development: Advancing clinical trial design. Nat. Rev. Drug Discov. 2009, 8, 949-957.

41. Gomez-Lechon, M.J.; Lahoz, A.; Gombau, L.; Castell, J.V.; Donato, M.T. In vitro evaluation of potential hepatotoxicity induced by drugs. Curr. Pharm. Des. 2010, 16, 1963-1977.

42. Baranczewski, P.; Stanczak, A.; Sundberg, K.; Svensson, R.; Wallin, A.; Jansson, J.; Garberg, P.; Postlind, H. Introduction to in vitro estimation of metabolic stability and drug interactions of new chemical entities in drug discovery and development. Pharmacol. Rep. 2006, 58, 453-472.

43. Medine, C.N.; Lucendo-Villarin, B.; Storck, C.; Wang, F.; Szkolnicka, D.; Khan, F.; Pernagallo, S.; Black, J.R.; Marriage, H.M.; Ross, J.A.; et al. Developing high-fidelity hepatotoxicity models from pluripotent stem cells. Stem Cells Transl. Med. 2013, 2, 505-509.

44. Guengerich, F.P. Cytochrome p450 and chemical toxicology. Chem. Res. Toxicol. 2008, 21, 70-83.

45. Rodrigues, A.D. Integrated cytochrome P450 reaction phenotyping: Attempting to bridge the gap between cDNA-expressed cytochromes P450 and native human liver microsomes. Biochem. Pharmacol. 1999, 57, 465-480.

46. Thummel, K.E.; Wilkinson, G.R. In vitro and in vivo drug interactions involving human CYP3A. Annu. Rev. Pharmacol. Toxicol. 1998, 38, 389-430.

47. Giacomini, K.M.; Huang, S.M.; Tweedie, D.J.; Benet, L.Z.; Brouwer, K.L.; Chu, X.; Dahlin, A.; Evers, R.; Fischer, V.; Hillgren, K.M.; et al. Membrane transporters in drug development. Nat. Rev. Drug Discov. 2010, 9, 215-236. 
48. Greenhough, S.; Medine, C.N.; Hay, D.C. Pluripotent stem cell derived hepatocyte like cells and their potential in toxicity screening. Toxicology 2010, 278, 250-255.

49. Yildirimman, R.; Brolen, G.; Vilardell, M.; Eriksson, G.; Synnergren, J.; Gmuender, H.; Kamburov, A.; Ingelman-Sundberg, M.; Castell, J.; Lahoz, A.; et al. Human embryonic stem cell derived hepatocyte-like cells as a tool for in vitro hazard assessment of chemical carcinogenicity. Toxicol. Sci. 2011, 124, 278-290.

50. Ghodsizadeh, A.; Taei, A.; Totonchi, M.; Seifinejad, A.; Gourabi, H.; Pournasr, B.; Aghdami, N.; Malekzadeh, R.; Almadani, N.; Salekdeh, G.H.; et al. Generation of liver disease-specific induced pluripotent stem cells along with efficient differentiation to functional hepatocyte-like cells. Stem Cell Rev. 2010, 6, 622-632.

51. Rashid, S.T.; Corbineau, S.; Hannan, N.; Marciniak, S.J.; Miranda, E.; Alexander, G.; Huang-Doran, I.; Griffin, J.; Ahrlund-Richter, L.; Skepper, J.; et al. Modeling inherited metabolic disorders of the liver using human induced pluripotent stem cells. J. Clin. Investig. 2010, 120, 3127-3136.

52. Zhang, S.; Chen, S.; Li, W.; Guo, X.; Zhao, P.; Xu, J.; Chen, Y.; Pan, Q.; Liu, X.; Zychlinski, D.; et al. Rescue of ATP7B function in hepatocyte-like cells from Wilson's disease induced pluripotent stem cells using gene therapy or the chaperone drug curcumin. Hum. Mol. Genet. 2011, 20, 3176-3187.

53. Wu, X.; Robotham, J.M.; Lee, E.; Dalton, S.; Kneteman, N.M.; Gilbert, D.M.; Tang, H. Productive hepatitis $\mathrm{C}$ virus infection of stem cell-derived hepatocytes reveals a critical transition to viral permissiveness during differentiation. PLoS Pathog. 2012, 8, e1002617.

54. Roelandt, P.; Obeid, S.; Paeshuyse, J.; Vanhove, J.; van Lommel, A.; Nahmias, Y.; Nevens, F.; Neyts, J.; Verfaillie, C.M. Human pluripotent stem cell-derived hepatocytes support complete replication of hepatitis C virus. J. Hepatol. 2012, 57, 246-251.

55. Schwartz, R.E.; Trehan, K.; Andrus, L.; Sheahan, T.P.; Ploss, A.; Duncan, S.A.; Rice, C.M.; Bhatia, S.N. Modeling hepatitis $\mathrm{C}$ virus infection using human induced pluripotent stem cells. Proc. Natl. Acad. Sci. USA 2012, 109, 2544-2548.

56. Ganem, D.; Prince, A.M. Hepatitis B virus infection--natural history and clinical consequences. N. Engl. J. Med. 2004, 350, 1118-1129.

57. Paganelli, M.; Dallmeier, K.; Nyabi, O.; Scheers, I.; Kabamba, B.; Neyts, J.; Goubau, P.; Najimi, M.; Sokal, E.M. Differentiated umbilical cord matrix stem cells as a newin vitromodel to study early events during hepatitis B virus infection. Hepatology 2013, 57, 59-69.

58. Taylor, J.M. Hepatitis delta virus. Virology 2006, 344, 71-76.

59. Yan, H.; Zhong, G.; Xu, G.; He, W.; Jing, Z.; Gao, Z.; Huang, Y.; Qi, Y.; Peng, B.; Wang, H.; et al. Sodium taurocholate cotransporting polypeptide is a functional receptor for human hepatitis B and D virus. Elife 2012, 1, e00049.

60. O’Shea, R.S.; Dasarathy, S.; McCullough, A.J. Alcoholic liver disease. Hepatology 2010, 51, 307-328.

61. D’Souza El-Guindy, N.B.; Kovacs, E.J.; de Witte, P.; Spies, C.; Littleton, J.M.; de Villiers, W.J.; Lott, A.J.; Plackett, T.P.; Lanzke, N.; Meadows, G.G. Laboratory models available to study alcohol-induced organ damage and immune variations: Choosing the appropriate model. Alcohol. Clin. Exp. Res. 2010, 34, 1489-1511. 
62. Seitz, H.K.; Stickel, F. Acetaldehyde as an underestimated risk factor for cancer development: Role of genetics in ethanol metabolism. Genes Nutr. 2010, 5, 121-128.

63. Pal, R.; Mamidi, M.K.; Das, A.K.; Gupta, P.K.; Bhonde, R. A simple and economical route to generate functional hepatocyte-like cells from hESCs and their application in evaluating alcohol induced liver damage. J. Cell. Biochem. 2012, 113, 19-30.

64. Szkolnicka, D.; Zhou, W.; Lucendo-Villarin, B.; Hay, D.C. Pluripotent stem cell-derived hepatocytes: Potential and challenges in pharmacology. Annu. Rev. Pharmacol. Toxicol. 2013, 53, 147-159.

65. Szkolnicka, D.; Farnworth, S.; Lucendo-Villarin, B.; Storck, C.; Zhou, W.; Iredale, J.P.; Flint, O.; Hay, D.C. Accurate prediction of potential liver injury using stem cell derived populations. Stem Cells Transl. Med. 2014, accepted for publication.

(C) 2013 by the authors; licensee MDPI, Basel, Switzerland. This article is an open access article distributed under the terms and conditions of the Creative Commons Attribution license (http://creativecommons.org/licenses/by/3.0/). 